\title{
Da corporeidade entre corpos Liminaridade vs continuum na performance
}

\author{
Anabela Pereira
}

\section{Introdução}

Pensar sobre a ideia de corporeidade entre corpos na performance implica, por um lado, a ideia de "liminaridade" de contingência ou de fronteira, i.e., de como se gera a interdependência entre os corpos a partir dos seus limites, a diferenciação, o encontro ou confronto, onde é que um acaba e o outro começa; por outro, a da "relação" entre ambos, a passagem entre esses "limiares" que ambos designam; o que acontece a partir dessas presenças mútuas como comunicam e se adaptam entre si. Donde, surge a noção de continuum, ou "continuidade", para invocar a ligação entre os corpos estabelecida através da percepção e do envolvimento simbólico no mundo. Em suma, da existência carnal a partir da qual partilhamos a "atenção" (pressupõe o envolvimento sensorial), o interesse e um entendimento mútuo sobre os mesmos objectos ou situação, neste caso, sobre a performance considerada na sua autonomia formal (cf. Tomasello et al. 2005 e Csordas 1993).

Pretende-se, assim, testar um paradigma para a interpretação dos sentidos da corporeidade na performance que apreenda o vivido em interacção, o compartilhado e os sentidos socialmente estabelecidos, apresentando um modelo de análise assente numa espécie de entendimento fenomenológico da experiência performativa, e que

Anabela Pereira é investigadora do CIES-IUL. Doutorada em Sociologia pelo ISCTE-IUL. Membro e tesoureira do Comité de Investigação - The

Body in the Social Sciences (RC54) -, da

Associação

Internacional de Sociologia. considera o corpo o foco da prática social - um corpo socialmente informado pela prática performativa (cf. Bourdieu 2009).

0 modelo opera a partir da substância viva do corpo, pois é "nos" e "através" dos nossos corpos que experimentamos o mundo, o que inclui a forma como estamos, nos apresentamos e interagimos com os outros. A sociologia da prática permite um olhar abrangente, para lá do micro olhar fenomenológico e interaccionista, i.e., considerar o corpo como base da vida colectiva e incluir o simbólico na análise. 0 entendimento concreto da performance é complementado pela análise dos modos

de ser e estar no mundo assentes nos métodos da fenomenologia e da sociologia da prática, conduzidos pelo paradigma da corporeidade, pois o corpo, mais que entidade biológica, é a condição necessária para a presença e o agir no mundo (cf. Csordas 1993 e 2008). A corporeidade representa, assim, um campo metodológico definido pela experiência perceptiva, presença e envolvimento na situação e foco na prática social (cf. ibid.). Neste modelo a corporeidade designa a condição existencial na qual a cultura performativa, as práticas e as experiências da performance, bem como o self se alojam (cf. idem 1993).

A ideia central é a de que o tempo-espaço da performance configura uma totalidade significante, embora esta nem sempre assuma uma forma reflexiva e objectivamente significada. 0 significado vai para além do simbólico ou imaginário, i.e., não está apenas na ideia de performance como representação ou linguagem com as suas estruturas e formas específicas de modulação, mas na ideia de performance enquanto experiência vivida em interacção e através da percepção. Esta perspectiva situa a análise da experiência performativa não onde ela "termina" - os objectos culturalmente constituídos (e.g. a obra) - mas sim onde ela "começa" - i.e., na percepção (na experiência vivida do corpo) - que não nos dá objectos acabados, mas perspectivas sempre renovadas do real (idem 2008: 105-107).

Esta abordagem pode servir como introdução a uma "fenomenologia da prática" ao expor um modelo de análise dos "processos internos" mobilizados na performance úteis para compreender os seus modos de operar e a sua "eficácia" simbólica; na qual o corpo é visto como agente activo e produtor de sentidos pelo envolvimento multissensorial no acontecimento performativo; um corpo que pode traduzir uma leitura da realidade, mas também é agente criador na sua essência carnal. Em suma, implica essencialmente: a plasticidade e o movimento dos corpos; a circularidade de processos sensoriais; os modos 


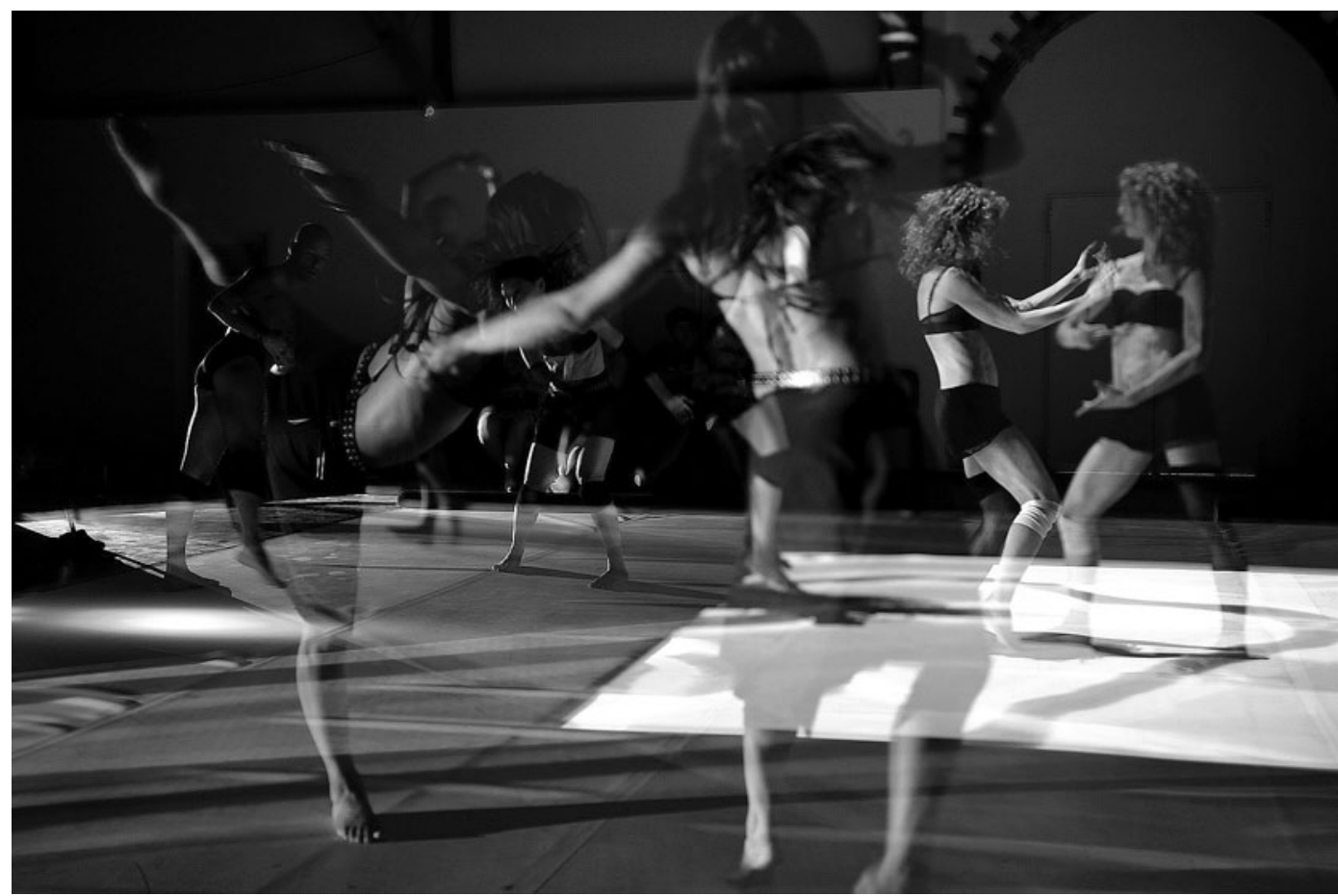

Colectivo Sonic Shuffle,

Festival Metasonic

Opensound 2012,

organização Granular, IPA fot. Nuno Martins.

somáticos de atenção (modos culturalmente definidos de se estar atento com e ao corpo num ambiente intersubjectivo); o envolvimento colaborativo no mundo (partilha de sentidos e intenções), e a socialidade do corpo:

A "socialidade do corpo" [...] coloca o organismo humano in situ, ou seja, em acto e em contexto, um organismo que age e interage, que apreende e modela o espaço que ocupa, plasticizado quer nas suas configurações estáticas (formas), quer nas suas propriedades dinâmicas (movimentos, gestos, mímica), a partir da sua inserção numa dada realidade histórica, da sua imersão num dado sistema social, políticoideológico, económico e simbólico situado no tempo e no espaço (Ferreira 2013: 499).

\section{A performance e o paradigma da corporeidade} Entendem-se por performativas as obras que exigem a presença do artista num espaço-tempo especifico, cuja criação tem como suporte essencial o seu próprio corpo, mas que nasceram sobretudo a partir da fusão de múltiplas expressões (música, dança, teatro, poesia, vídeo, etc.). 0 objectivo é interagir directamente com o público (e.g., a performance é feita in situ com o espectador muitas vezes envolvido no próprio trabalho), procurando através da plasticidade e na imediação dos corpos a sua própria substância.

A performance consiste, pois, num acontecimento, com carácter efémero e imaterial (eventualmente registado em fotografias, vídeos ou desenhos preparatórios) cujo sentido extravasa o artístico para se constituir, também, como aqui demonstramos, no âmbito da fenomenologia (como desempenho somático) e da sociologia (como desempenho prático).

A análise da performance permite demonstrar que a "atenção", a "plasticidade" e o "movimento" constituem os mecanismos pelos quais é possivel construir os sentidos da corporeidade, suportados pela tangibilidade dos corpos em interacção, ao encarnarem ou materializarem os valores comuns e as práticas que emergem do seu uso contextual.

Defende-se que a expressividade do artista confere à obra o seu sentido, a partir da presença e de improvisos gerados dentro dos limites do corpo em interacção. $\mathrm{Na}$ ampliação dessa experiência e agenciamento de sentidos ao corpo do espectador estabelece-se uma continuidade dialógica entre corpos que integra a obra enquanto totalidade concreta e/ou autónoma. Desta forma sobressai como "acto comunicativo original" - intersubjectivo onde o sentido não existe objectivado a priori, nasce com a experiência (cf. Csordas 1993: 115) ${ }^{1}$. Nomeadamente, através dos "modos somáticos de atenção" ou "processos multissensoriais através dos quais experimentamos com os nossos corpos um mundo habitado por outros" (ibid.). 0 que envolve as práticas e a aprendizagem (onde se incluem o automatismo, o inconsciente cognitivo, a cognição, a reflexividade); o contexto e a forma como se produzem os vários estilos de desempenho. Estes são factores indispensáveis para a compreensão de um mundo de práticas corporalizadas.

De acordo com o modelo de Tomasello et al. (2005: 689) o "percurso ontogenético do envolvimento social dos individuos" requer: a) a compreensão das acções: práticas que implicam o envolvimento colaborativo e a partilha de valores, emoções e comportamentos; b), a compreensão da construção de sentidos do envolvimento simbólico (partilha de objectivos e percepções); c), conhecer o envolvimento cultural dos indivíduos em contextos particulares, que partilham intenções e atenção sobre os mesmos objectos/momento.

\section{Movimento, somatização e interacção}

Esta proposta demonstra as conexões entre as estruturas da actividade corporal e as operações cognitivas mais elementares, pois a compreensão do mundo depende das formas de raciocínio enraizadas nos padrões da actividade
'Csordas (1993: 115116) recorre ao conceito de "pré-objectivo" de Merleau-Ponty (para superar a distinção sujeito-objecto, pois a percepção começa no corpo e não nos objectos, i.e., os objectos só existem quando tomamos consciência deles) e de habitus de Bourdieu (para superar a dicotomia estrutura-prática; o corpo socialmente informado é o principio unificador de todas as práticas). 
corporal. 0 "movimento" é elementar nesta abordagem, pois representa a categoria central do sistema corporal, da somatização e da interacção humana. Na performance o movimento é a base de todas as manifestações expressivas do corpo desde a maquilhagem e adornos, às formas de apresentação e técnicas corporais como coreografias, gestos e posturas.

Merleau-Ponty (1994) analisou as características da "reversibilidade dos sentidos" (funções aferentes e eferentes do sistema nervoso ${ }^{2}$ ) no processo de organização do movimento do sistema sensório-motor. A noção remete para a "circularidade" entre processos corporais e estados neuronais, entre corpo e mente, e demonstra que o sentido dos acontecimentos está na condição corporal (com as capacidades sensoriais e motoras como unidade dinâmica) e não num sujeito desencarnado.

As neurociências (e.g., Damásio 2010) destacam também a importância do movimento na acção, indicando que a resposta neuronal resulta da circularidade entre acontecimentos internos e externos do organismo e que a mente emerge das interacções cérebro-corpo. A percepção não descodifica só estímulos, reflecte a estrutura do corpo face ao meio, em contextos sociais, culturais e afectivos múltiplos. Também as ciências da saúde e do desporto demonstram como práticas e ritmos do corpo têm um efeito na consciência e no controlo de várias questões de ordem corporal, que afectam não só o desempenho somático, mas psicológico e social. 0 que significa, também, compreender a performance como uma espécie de "ontogénese" i.e., como resultado de um "envolvimento colaborativo", em que os actores estruturais da acção performer e espectador - partilham a atenção sobre os mesmos objectos, detêm um entendimento comum da situação, com a comunicabilidade de percepções e intenções - "intencionalidade compartilhada" (Tomasello et al., 2005: 675-689). A participação neste tipo de actividades requer leituras e formas específicas de aprendizagem cultural, mas também uma motivação única para partilhar estados de espírito e formas de representação cognitiva para o fazer, que acarretam estratégias de adaptação como a plasticidade, a criatividade, a reflexividade e capacidade de integração, objectivos e estímulos comuns (cf. ibid.).

Logo, o corpo performativo é visto como uma unidade dinâmica multissensorial que permite experienciar a situação, mas também como um corpo prático e construção socio-simbólica. Um corpo socialmente informado de socialidade e cultura, modelado a partir da inserção na realidade processual da obra, da imersão numa dada atmosfera conceptual, ao mesmo tempo perceptiva, social e simbólica. Ou seja, por estruturas e disposições performativas interiorizadas pelo artista e por representações sociais sobre a própria performance veiculadas (na e pela carne) enquanto sua actividade ou desempenho profissional (cf. Ferreira 2013: 517; Csordas 1993: $115-116$ e 2008: 105-107).

0 corpo vivido na performance é duplamente assumido como corpo que constrói e é construído pela actividade do artista. Enquanto organismo vivo e sensório-motor é a partir das suas potencialidades perceptivas, cinéticas e sensitivas que se apropria, age sobre e interage com a situação. Nas suas encenações, gestos e posturas, o corpo performativo é vivido e construido em resposta/continuidade à totalidade contextual percepcionada (carnal e simbolicamente) nos seus modos práticos.

A ideia de continuidade na performance coloca a possibilidade da sua extensão no futuro (individualmente transformando-a em memória, em experiência, disposições ou conhecimento incorporado, colectivamente em narrativa ou história). 0 artista torna-se presente ao expor/agir a obra. Ao fazê-lo reflecte o lugar do espectador, do outro, vive essa relação - identidade versus alteridade, que caracteriza também a dialéctica dos corpos na performance -, abrindo diálogos entre eles. 

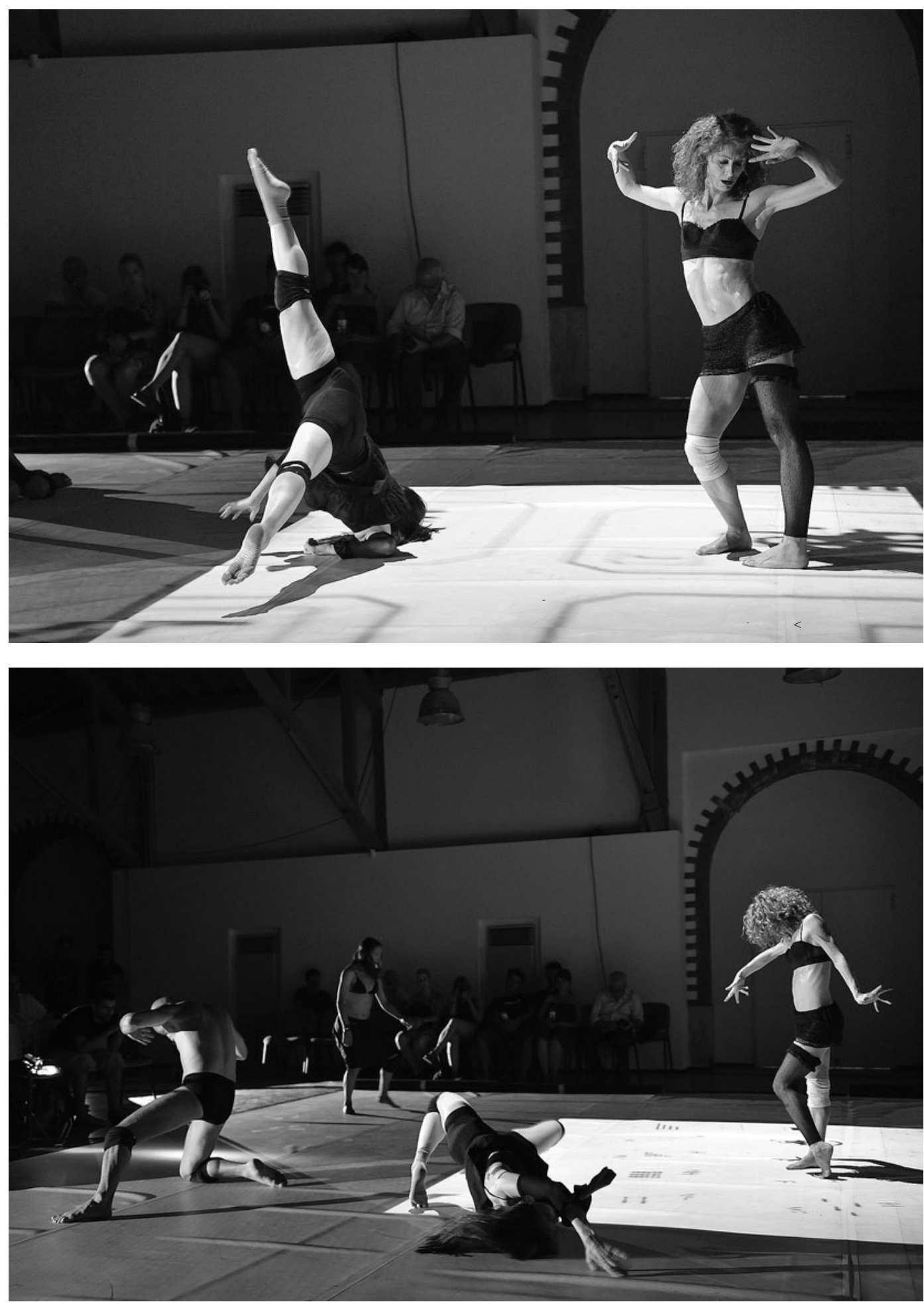

$\wedge<$

Colectivo Sonic Shuffle, Festival Metasonic Opensound 2012, organizaçãao Granular, IPA fot. Nuno Martins
Componentes do modelo de análise da performance (para uma fenomenologia da prática)

\section{Plasticidade}

Movimento (desempenho somático e desempenho prático) Circularidade de processos sensoriais Modos somáticos de atenção

Envolvimento colaborativo no mundo Sociabilidade do corpo

Diálogo de corpos

\section{Conclusão}

Entre a fronteira somático-simbólica e a proximidade dialógica com o artista, o público torna-se um vector indispensável da performance, no âmbito do qual esta encontra inteligibilidade. Ou seja, ela existe num espaço que é, simultaneamente, o da transcendência dos corpos e o das suas contingências liminares, agenciada pelas suas potencialidades dialógicas. Ela existe e não existe, porque ganha vida só quando realizada, bem delimitada no espaço e no tempo e composta da unidade viva das suas partes - os corpos em interacção; bem como, de um 


\section{Referências bibliográficas}

sentido lógico que permite percebê-la como um universo coerente e não como um caos impressivo.

A interacção com o cenário, o espectador, o chão, etc., mostra a vontade do artista para partilhar esse espaço liminar entre corpos que a obra constitui, tornando-os parte da cena como objectos. A fronteira dos corpos não constitui uma ruptura, representa, na potencialidade da sua extensão, a possibilidade de existência da obra. Esta concepção admite uma ideia de sentido e de acção ligados não só a representações discursivas dos corpos, antes, imanentes a todos os modos de actuação e vivência, a todas as práticas e a uma consciência perceptiva donde emana todo 0 acto performativo. 0 acto performativo aperfeiçoa-se através da interacção humana, oferecendo orientações de sentido, com o corpo individual como zona de mediação na qual os limites entre o interno e o externo entre 0 artista e o outro se ampliam na abertura ao diálogo, de certa forma, imposto pela presença dos corpos.
BOURDIEU, Pierre (2009), O sentido prático [1980], Petrópoles, Editora Vozes.

CSORDAS, Thomas J. (1993), "Somatic Modes of Attention", in Cultural Anthropology, Vol. 8, No. 2 (May, 1993), pp. 135-156, Pub., Wiley, Article Stable URL: <http://www.jstor.org/stable/656467>

-- (2008), Corpo, significado, cura, Porto Alegre, Ed. UFRGS.

DAMÁSIO, António (2010), O livro da consciência: A construção do cérebro consciente, Maia, Temas \& Debates.

FERREIRA, V. Sérgio (2013), "Resgates sociológicos do corpo: esboço de um percurso conceptual", Análise Social, 208, XLVIII (3. ), pp. 493598. Lisboa, ICS. ISSN Online 2182-2999.

MERLEAU-PONTY, M. (1994), Fenomenologia da percepção [1945], S. Paulo, Martins Fontes.

TOMASELLO, Michael et al. [CARPENTER, Malinda / CALL, Josep / BENHE, Tanya / MOLL, Henrike ] (2005), "Understanding and Sharing Intentions: The Origins of Cultural Cognition", in Behavioral and Brain Sciences (2005) 28, 675-735. USA, Cambridge University Press. (Online) Available at: http://email.eva.mpg.de/ tomas/pdf/BBS_Final.pdf [data de acesso: 03-03-2012]. 